\title{
Reviewing 15 years of experience with sirolimus
}

\author{
Helio Tedesco Silva Jr', Claudia Rosso Felipe and Jose Osmar Medina Pestana
}

\begin{abstract}
Here, we review 15 years of clinical use of sirolimus in our transplant center, in context with the developing immunosuppressive strategies use worldwide. The majority of studies were conducted in de novo kidney transplant recipients, using sirolimus (SRL) in combination with calcineurin inhibitors (CNIs). We also explored steroid (ST) or CNI-sparing therapies, including CNI minimization, elimination, or conversion strategies in combination with mycophenolate (MMF/MPS). Pooled long-term outcomes were comparable with those obtained with CNI and antimetabolite combination. Surprisingly, there are still several areas that need further investigation to improve the risk/benefit profile of SRL in kidney transplantation, including pharmacokinetic/pharmacodynamic drug-to-drug interaction with cyclosporine (CSA) or tacrolimus (TAC), mechanisms of SRL-associated adverse reactions and combinations with other drugs such as belatacept and once-daily TAC, possibly leading to improved long-term adherence. These studies, along with others investigating the benefits of SRL associated lower viral infections and malignancies, are essential as we do not expect the introduction of new immunosuppressive drugs in the near future.
\end{abstract}

\section{Introduction}

Beginning on June 1999, we started exploring alternative immunosuppressive regimens using sirolimus (SRL). We began our experience by combining SRL with progressive reduction in cyclosporine (CsA) exposure in de novo kidney transplant recipients. This initial experience was followed by studies exploring SRL exposures combined with reduced CsA exposure in black patients, early CsA minimization or elimination strategies and the use of SRL in calcineurin inhibitor (CNI)-free regimens combined with mycophenolate (MMF). With the increasing use of tacrolimus (TAC) in de novo kidney transplant recipients, we also conducted a head-to-head comparison of SRL with MMF followed by another study comparing steroid (ST) or TAC withdrawal in kidney transplant recipients receiving de novo therapy with SRL. Later, we began to explore conversion strategies, either late or early conversions from CNI to SRL.

\footnotetext{
* Correspondence: heliotedesco@hrim.com.br

Nephrology Division, Hospital do Rim, Escola Paulista de Medicina, Universidade Federal de São Paulo, São Paulo, Brazil
}

\section{De novo kidney transplant recipients}

In our first open-label randomized trial, we compared the safety and efficacy of $2 \mathrm{mg}$ fixed daily doses of SRL with $2 \mathrm{mg} / \mathrm{kg}$ fixed daily doses of azathioprine (AZA) in living related renal allograft recipients receiving CsA and ST [1]. Because first reports suggested the potentiation of CsA nephrotoxicity by SRL [2, 3], we attempted to implement a small reduction in CsA exposure. In this study, CsA concentrations were lower in patients receiving SRL compared to AZA from week 4 ( $247 \mathrm{vs.} 309 \mathrm{ng} / \mathrm{mL}, p$ $=0.04$ ) to month 12 (143 vs. $188 \mathrm{ng} / \mathrm{mL}, p=0.045)$. The incidence of the primary composite endpoint (biopsy confirmed acute rejection, graft loss, or death) was lower in SRL group at 3 months ( 0 vs. $17.1 \%, p=0.025)$ but not at 12 months (11.4 vs. $14.3 \%$, ns). The relatively small reduction in CsA exposure was associated with no difference in mean serum creatinine at 12 months $(1.8 \pm 0.6$ vs. $1.6 \pm$ $0.6 \mathrm{mg} / \mathrm{dL}, p=0.23$ ) but the small sample size may not had sufficient power to detect the small difference observed. Therefore, we decided to expand our experience to reach 90 patients receiving $2 \mathrm{mg}$ fixed daily doses of SRL [4]. At 12 months, mean whole blood CsA trough concentrations were $100 \mathrm{ng} / \mathrm{mL}$ in patients receiving SRL and $200 \mathrm{ng} / \mathrm{mL}$ in patients receiving AZA. Retrospective analysis showed that mean whole blood SRL trough concentrations 
increased from day 7 to months 1 and $12(5.2 \pm 3.1$ vs. 7.5 \pm 3.6 vs. $8.4 \pm 6.0 \mathrm{ng} / \mathrm{mL}, p<0.0001)$ with a tenfold interindividual variability, ranging from 2.5 to $23.5 \mathrm{ng} / \mathrm{mL}$. There was no difference in 1-year composite efficacy endpoint comparing SRL and AZA groups (18 vs. $20 \%$ ) or in the incidence of biopsy-proven acute rejection (14.4 and $14.3 \%)$. Importantly, even with higher sample size, we were unable to detect difference in mean serum creatinine $(1.65 \pm 0.46$ vs. $1.60 \pm 0.43 \mathrm{mg} / \mathrm{dL}, p=0.48)$ or in mean calculated creatinine clearances $(61 \pm 15$ vs. $62 \pm 13 \mathrm{~mL} /$ $\min , p=0.58)$ at 1 year. At that time, we concluded that the use of SRL and reduced CsA exposure was effective in preventing acute rejection and preserving allograft function.

Brazil has a highly miscegenated population with African ancestry that is at an increased risk for renal allograft failure [5]. Knowing that studies had demonstrated that black patients requires higher doses of SRL to achieve comparable efficacy compared to the Caucasian population [6], we designed a study to identify optimal therapeutic SRL concentrations in black kidney transplant recipients receiving reduced CsA exposure and prednisone [7]. Black patients received CsA, ST, and 5mg fixed doses of SRL till day 7 when they were randomized to maintain whole blood SRL trough concentrations between 8 and 12 or 15 and $20 \mathrm{ng} / \mathrm{mL}$. There was no difference in mean whole blood CsA trough concentrations at months $1(182 \pm 86$ vs. $162 \pm 87 \mathrm{ng} / \mathrm{mL})$ and 12 months $(62 \pm 43$ vs. $59 \pm 52 \mathrm{ng} / \mathrm{mL}$ ). At 6 months, mean whole blood SRL trough concentrations were $10.8 \pm 5.8$ vs. $18.0 \pm 6.1 \mathrm{ng} / \mathrm{mL}$ $(p<0.001)$. The incidence of biopsy-proven acute rejection was higher in the lower SRL concentration group (18 vs. $8 \%$ ). Mean calculated creatinine clearance was higher in the lower SRL concentration group ( $64.5 \pm 17$ vs. $54.4 \pm 14.7 \mathrm{~mL} / \mathrm{min}, p=0.011$ ) despite higher incidence of acute rejection. The incidence of post-transplant diabetes mellitus was $13 \%$ and no CMV disease was observed. Higher SRL concentrations were associated with higher efficacy but lower renal function, further emphasizing the complex interaction between these two drugs [8].

To further investigate the interaction between SRL and CsA, we performed a sequencial pharmacokinetic study at days 7, 30, and 90 in kidney transplant recipients receiving 2- or 5-mg fixed daily doses of SRL. Both SRL and CSA showed moderate to high inter (39 to 70 and 33 to $52 \%$ ) and intra (30 to 41 and 25 to $43 \%)$ subject variability, respectively. A threefold increase in SRL concentrations (4.7 to $14.3 \mathrm{ng} / \mathrm{mL}$ ) resulted in $37 \%$ increase in mean CSA AUC $(6,654$ to $9,133 \mathrm{ng} . \mathrm{h} / \mathrm{mL}, p=0.007)$. Similarly, a 1.8 -fold increase in CSA concentrations (190 to $345.5 \mathrm{ng} / \mathrm{mL}$ ) resulted in $115 \%$ increase in mean SRL AUC (199.8 to $428.9 \mathrm{ng} . \mathrm{h} / \mathrm{mL}, p=0.002$ ). These results confirmed the unpredictable and complex pharmacokinetic interactions between SRL and CSA in kidney transplant recipients [9].

In two phase II trials in patients receiving AZA/ST [10] or MMF/ST [11] and no induction therapy, higher incidence of acute rejection was observed in those treated with SRL compared to those receiving CsA. The lack of adequate efficacy of CNI-free regimens without induction therapy, along with the complex synergistic interaction between CsA and SRL, led to studies exploring elimination or minimization of CsA, to obtain maximal early efficacy for the prophylaxis of acute rejection and prevention of long-term CsA-associated toxicities $[12,13]$. Our multicenter national phase 4, open-label, randomized (1:1) trial conducted in nine centers investigated the safety and efficacy of concentration-controlled use of SRL and CsA followed by CsA minimization or elimination beginning at week 13 [14]. At 12 months, there were no differences in renal function (61.08 vs. $65.24 \mathrm{~mL} / \mathrm{min}, p=0.132$ ), incidence of biopsy-confirmed acute rejection ( 14.3 vs. $22.5 \%, p=0.152$ ). There were no differences in the overall rate of study-drug discontinuation ( 32.4 vs. $36.3 \%, p=0.562$ ) but more patients discontinued because of lack of efficacy/graft loss in the CsA elimination group ( 4.8 vs. $14.7 \%, p=0.018$ ). In summary, CsA minimization or elimination offers treatment options for de novo renal allograft recipients $[15,16]$. Although few studies have systematically investigated the ideal CsA exposure in combination with SRL, it has been suggested that up to $80 \%$ reduction can be used with even superior efficacy compared to full CsA exposure, with or without SRL [17].

The growing number of kidney transplant recipients receiving TAC and MMF prompted us to compare it with the combination of TAC and SRL [18]. Kidney transplant recipients receiving TAC-based immunosuppressive regimen were randomized to receive fixed daily doses of MMF (2 g/day) or SRL (one loading dose of $15 \mathrm{mg}, 5 \mathrm{mg} /$ day till day 7 , and $2 \mathrm{mg} /$ day thereafter) without induction therapy. Mean whole blood TAC concentrations among patients receiving MMF or SRL were similar at $1(10.4 \pm 4.0$ vs. $9.8 \pm 3.2 \mathrm{ng} / \mathrm{mL})$ and 12 $(6.9 \pm 2.3$ vs. $7.1 \pm 2.5 \mathrm{ng} / \mathrm{mL})$ months. Mean plasma mycophenolic acid (MPA) trough concentrations were $2.9 \pm 1.7$ and $3.6 \pm 2.2 \mathrm{mg} / \mathrm{L}$, and mean whole blood SRL trough concentrations were $4.2 \pm 1.8$ and $6.6 \pm 3.5 \mathrm{ng} /$ $\mathrm{mL}$, at 1 and 12 months, respectively. No differences were observed in the incidence of biopsy-confirmed acute rejection (12 vs. $14 \%, p=1.000$ ). Patients receiving SRL showed higher mean serum creatinine $(1.6 \pm 0.5$ vs. $1.4 \pm 0.3 \mathrm{mg} / \mathrm{dL}, p=0.007$ ), higher proportion of patients with proteinuria (52.0 vs. $10.7 \%, p=0.041$ ), higher mean urinary protein concentrations $(0.3 \pm 0.5$ vs. $0.1 \pm 0.2 \mathrm{~g} /$ $\mathrm{L}, \quad p=0.012)$, higher mean cholesterol concentration (217 vs. $190 \mathrm{mg} / \mathrm{dL}, p=0.030$ ), and higher proportion of 
patients prematurely discontinued from randomized therapy ( 26 vs. $8 \%, p=0.031$ ). Similar findings were observed in large international multicenter trials [19, 20]. Similar to the CsA clinical experience, more recent studies have shown that lower TAC concentrations should be used combined with SRL [21] and that TAC discontinuation in patients receiving SRL was associated with increased incidence of acute rejection [22].

During mid-2000s, with the approval of the anti-IL-2R blockers for induction therapy, several trials of ST or CNI avoidance or withdrawal were conducted, all with the purpose of improving long-term tolerability and safety of immunosuppressive regimens. With the premise from previous studies, we decided to explore whether SRL would be effective in CNI-free or ST-free regimen. We first evaluated the efficacy and safety of two CNIfree regimens in low-risk recipients of one haplotype living-related kidney transplants [23]. Immunosuppression consisted of TAC, AZA, and ST vs. two doses of daclizumab, MMF, and STvs. two doses of daclizumab, MMF, SRL, and ST. At 12 months, the incidence of BCAR was higher in patients receiving CNI-free regimes (10.5 vs. 48.5 vs. $24.0 \%, p<0.01$, respectively). In patients of black ethnicity, the incidence of acute rejection was higher in the MMF/ST group (25 vs. 83.3 vs. $20 \%, p=0.055)$, respectively. There were no differences in mean calculated creatinine clearance at 12 months $(58.9 \pm 14.0, \quad 56.9 \pm 16.4, \quad 59.3 \pm 21.4 \mathrm{~mL} / \mathrm{min})$. Overall incidence of post-transplant diabetes mellitus (3.3\%) and cytomegalovirus disease (4.3\%) was similar in all groups. It was then clear that CNI-free regimen, with MMF or SRL/MMF, would not sustain low rates of acute rejection, as demonstrated in multicenter international trials [24-26].

Subsequently, we explored early discontinuation of either CNI or ST. Recipients of first renal transplant received SRL, TAC, and ST without induction therapy and were randomized to undergo ST (SRL/TAC) or TAC (SRL/ST) withdrawal 3 months after transplantation [27]. Lower mean whole blood SRL trough concentration was observed in patients receiving SRL/TAC compared to SRL/ST $(11.5 \pm 3.0$ vs. $15.3 \pm 4.5 \mathrm{ng} / \mathrm{mL})$. No differences were observed in the incidence of BCAR (4.2 vs. $9.5 \%$ ). Mean calculated creatinine clearance was comparable $(60 \pm 11.5$ vs. $63.4 \pm 10.5 \mathrm{~mL} / \mathrm{min})$, and no significant differences were observed in the proportion of patients with proteinuria at 12 months ( 20 vs. $30.7 \%, p=$ 0.629), respectively. We observed a higher incidence of lymphocele or lymphorrhea (13 vs. $4.1 \%$ ), proteinuria (13 vs. $8.3 \%$ ), graft dysfunction (17.3 vs. $4.1 \%$ ), stomatitis (30.4 vs. $8.3 \%$ ), headache (56.5 vs. $33.3 \%$ ), leucopenia (8.6 vs. $0 \%$ ), thrombocytopenia (8.6 vs. $4.1 \%$ ), dyslipidemia (78.2 vs. $66.7 \%$ ), and CMV infection (4.3 vs. $0 \%$ ) in SRL/ ST group. The incidence of NODAT (10.6\%) was similar between groups. Higher mean cholesterol concentration was observed in the SRL/ST group $(191.9 \pm 63.3$ vs. $241.6 \pm 61.5 \mathrm{mg} / \mathrm{dL}, p=0.019)$. Treatment discontinuation due to adverse events occurred in $12.5 \%$ of patients in SRL/TAC group and $21.7 \%$ in SRL/ST group. Within 12 months of observation, our study was unable to detect any significant difference in major transplant outcomes comparing $\mathrm{CNI}$ and ST elimination strategies. In this context, a recent review concluded that the benefits of minimizing immunosuppression, either ST or CNI, must be weighed against the risks of precipitating acute rejection or chronic allograft dysfunction [28].

These exploratory studies conducted in de novo kidney transplant recipients allowed us to perform a 10year retrospective analysis of pooled data from patients included in prospective randomized trials in de novo kidney transplant recipients receiving CNI combined with SRL $(n=329)$ or AZA/MMF $(n=124)$. We did not observe differences in patient (89.1 vs. 91.1, $p=0.766$ ), graft (72.9 vs. $76.6 \%, p=0.709)$, and biopsy-confirmed acute rejection-free (78.1 vs. $79.0 \%, p=0.976$ ) survivals, respectively. The incidence of $\mathrm{CMV}$ infection was lower (6 vs. $11 \%, p=0.024$ ), but treatment discontinuation was higher among patients receiving SRL (66 vs. $31.5 \%$, $p<0.001)$, respectively. At 5 years, mean estimated glomerular filtration rates were comparable $(57.4 \pm 18.6$ vs. $57.0 \pm 19.2 \mathrm{~mL} / \mathrm{min}, p=0.111$ ) but the proportion of patients with proteinuria was higher among patients receiving SRL (44 vs. $19 \%, p<0.001$ ), respectively [29].

\section{Critical analysis}

The interest for the clinical use of SRL and CNI in de novo kidney transplant recipients has reduced since its approval in early 2000. The basic reason behind this observation is perhaps the lack of a thorough understanding of the interaction between these two drugs. Although the pharmacokinetic interaction between SRL and CsA was anticipated, high doses and concentrations of both SRL and CsA or TAC were used initially, leading to a disproportionally higher incidence of adverse events, poor tolerability, and ultimately drug discontinuation. Key adverse events of this drug combination have been associated with higher concentrations of both drugs, namely, wound healing [30] and inferior renal function [31]. Not surprisingly, two registry analyses showed inferior graft survival in patients receiving SRL combined with CsA [32] or TAC [33].

Alternatively, CNI avoidance and withdrawal trials were implemented to avoid or minimize this drug interaction. A recent systematic review and meta-analysis of randomized controlled trials showed higher incidences of acute rejection but superior renal functions with no differences in patient or graft survival were observed at 1 year after transplantation [34]. Nevertheless, a registry 
analysis confirmed that a CNI-free immunosuppressive regimen consisted of SRL/MMF combination was associated with inferior renal transplant outcomes compared to CNI combined with SRL or MMF [35]. Two main reasons emerge from this observation. First, SRL and MMF share similar profile of adverse events such as gastrointestinal and bone marrow toxicities. Second, recent data have suggested the increased risk of acute rejection or chronic antibody-mediated rejection in presents with suboptimal CNI exposure [28]. Therefore, more studies exploring different drug concentrations are needed to define proper doses of both drugs associated with a more favorable short- and long-term efficacy/ safety profile [36]. Nevertheless, prospective trials are required to define therapeutic concentrations for both drugs associated with best efficacy/toxicity ratios.

\section{Conversion strategies}

Our first experience with conversion from CNI to SRL occurred during the Sirolimus Renal Conversion Trial (CONVERT) [37]. This study explored late conversion, mean time after transplantation of 37 months, from CNI to SRL. The primary efficacy endpoint, Nankivell GFR in the intent-to-treat (ITT) population 12 months after randomization, was comparable $(59.0$ and $57.7 \mathrm{~mL} / \mathrm{min}$ ) in the cohort of patients with baseline GFR more than $40 \mathrm{~mL} / \mathrm{min}$. Conversion was associated with no difference in the incidence of acute rejection, increased urinary protein excretion, and a lower incidence of malignancy compared with CNI continuation. Treatment discontinuation was higher in SRL conversion versus CNI continuation patients at 12 (15.7 vs. $9.5 \%$, respectively, $p=0.013)$ and 24 ( 25.8 vs. $20.0 \%, p=0.070)$ months. Superior renal function was observed among patients who remained on SRL through 12 to 24 months, particularly in the subgroup of patients with baseline GFR more than $40 \mathrm{~mL} /$ min and proteinuria less than or equal to 0.11 .

Following the initial promising data of the Spare the Nephron trial [38], we designed our multicenter, prospective, open-label, national trial with planned conversion from TAC to SRL 3 months after kidney transplantation. Of 297 patients initially treated with TAC, MPS, and ST, 283 patients reached 3 months of whom 97 were converted to SRL, 107 were maintained on TAC, and 79 were patients receiving TAC without criteria to undergo intervention. There was no difference in the primary objective, superior estimated glomerular filtration rate in the SRL group at month 24 in the intention-to-treat population $(66.2 \pm 25.3$ vs. $70.7 \pm 25.1 \mathrm{~mL} / \mathrm{min}, p=.817)$. There was also no difference in the severity of chronic sclerosing lesions scores in 24-month protocol biopsies. Higher mean urinary protein-to-creatinine ratio $(0.36 \pm 0.69$ vs. $0.15 \pm$ $0.53, p=0.03)$ and higher incidence of treated acute rejection between months 3 and $24(13.4$ vs. $4.7 \%, p=047)$ were observed in SRL compared to TAC group [39]. Interestingly, comparable results were observed in a multicenter international trial with similar design [40].

\section{Critical analysis}

Late conversion from CNI to SRL has not been consistently associated with significant improvement in renal function. Nevertheless, the trials identified risk factors associated with poor clinical therapeutic response, including the level of renal function, proteinuria, and structural damage [41]. Early conversion trials, while excluding patients with these risk factors, were associated with loss of efficacy, lower tolerability and increased incidence of adverse events. In one study, 192 kidney transplant recipients receiving CsA, MMF, and ST were converted to SRL $(n=95)$ at 3 months or continued CsA $(n=97)$ and underwent planned ST discontinuation at month 8 (CONCEPT) [42]. At 12 months, the incidence of acute rejection was higher (17 vs. $8 \%, p=0.071)$ but renal function was superior in patients converted to SRL (68.9 vs. $64.4 \mathrm{~mL} / \mathrm{min} / 1.73 \mathrm{~m}^{2}, p=0.017$ ) compared to those maintained on CsA. Interestingly, the incidence of subclinical inflammation in protocol biopsies performed at 12 months (30.6\%) was higher in the SRL compared to CsA group (45.2 vs. $15.3 \%$ ) and associated with lower estimated glomerular filtration rate $(50.8 \pm 13.3$ vs. $57.7 \pm$ $\left.16.3 \mathrm{~mL} / \mathrm{min} / 1.73 \mathrm{~m}^{2}, p=0.035\right)$ at 30 months [43]. Furthermore, no significant differences were observed in the incidence of interstitial fibrosis comparing both groups [44]. In an extension study, renal function was superior in SRL $(n=77)$ compared to CsA $(n=85)$ group at 48 months (62.6 vs. $\left.57.1 \mathrm{~mL} / \mathrm{min} / 1.73 \mathrm{~m}^{2}, p=0.013\right)$ [45].

Taken together, when choosing this immunosuppressive strategy, one needs to balance the risks of early subclinical and clinical rejection and the long-term benefits of superior renal function. Better understanding of risk factor for acute rejection, using more robust diagnostic methods, may increase the success of these strategies. Low tolerability may be associated with factors intrinsic to the drug (aftous ulcers, dyslipidemia, peripheral edema) but others emerge as a consequence of overlapping toxicity profile of MPA and SRL [46]. Better partners such as belatacept may improve the long-term safety of SRL [47]. More studies aiming to investigate SRL-associated proteinuria using different immunosuppressive strategies after kidney transplantation is essential to increase the safety of these regimens [48]. In this direction, a multicenter prospective trial demonstrated that the use of ramipril prior to early conversion from CNI to SRL is associated with lower incidence of proteinuria during the first 12 months [49].

The association of SRL with lower incidence of viral infections is opened for various types of investigation [50]. Significant reductions in the incidence of CMV 
[51] and BKV [52] infections have been reported in patients receiving SRL. Cancers with higher relative incidence among kidney transplant recipients compared to the general population are associated with viral infection such as Kaposi sarcoma (herpesvirus 8), non-Hodgkin lymphomas (EBV), and skin cancer (HPV) [53]. The association between SRL and lower incidence of cancer will be explored in the future [54], as death due to cancer contributes increasingly to the overall death rate among kidney transplant recipients (http://www.anzdata.org.au/anzdata/AnzdataReport/31stReport/Ch10CancerReport.pdf). The association of SRL and reduced recurrence of non-melanoma skin cancer was well documented in three independent international multicenter trials [55-57]. Nevertheless, the benefit observed was mitigated by the low tolerability of the SRL-containing immunosuppressive regimen.

\section{Future perspectives}

It is surprising that even after 15 years of clinical use, SRL-based immunosuppressive regimens are still evolving. More importantly, several areas of research are still open for future studies. Comprehensive understanding the complex pharmacokinetic and pharmacodynamics interaction between SRL and CNI will be decisive to investigate and define target concentrations for both classes of drug, either in de novo or as a conversion strategy. In experimental models, dose-dependent biochemical metabolite patterns differences were observed in the brain [58] and in the kidney [59] when combining SRL or EVR with CsA, suggesting that SRL potentiates CsA-induced mitochondrial dysfunction. Nevertheless, whether this metabolic difference is translated into measurable clinical differences in outcomes or renal function is not known as there is no head-to-head comparison of these two drugs using CNI minimization strategies. This will be even more important because sotrastaurin $[60,61]$ and tofacitinibe [62] drug development program were prematurely terminated and no new drugs are expected to be approved for clinical use soon. The effects of SRL in reducing the incidence of viral infections and malignancies may influence transplant outcomes as long as we increase safety and tolerability of SRL-containing immunosuppressive regimens. Promising strategies include the combination of SRL with once-daily TAC or belatacept. While the first once-daily TAC formulation of TAC has already been used in the clinical setting [63], a new formulation has finished phase three trials and will soon be registered [64]. The pharmacokinetics, efficacy, and safety of the combination of SRL with once a day TAC should be investigated in future studies, including methods to measure the influence of adherence on transplant outcomes. A pilot study in de novo kidney transplant recipients receiving rabbit anti-thymocyte globulin and short course of ST showed similar efficacy and $8-10 \mathrm{~mL} / \mathrm{min}$ higher glomerular filtration rate at 12 months compared with TAC/ MMF [47]. Furthermore, while SRL has been associated with increasing regulatory $\mathrm{T}$ cells [65], belatacept has been associated with lower incidence of de novo donorspecific antibodies [66]. In summary, although several SRL-contained immunosuppressive strategies have already been tested in solid organ transplantation over the last 20 years, many more studies are needed to allow our patients to fully benefit from this therapy in the future.

\section{Competing interests}

Helio Tedesco-Silva has received speaker's fees and travel or accommodation expenses fordevelopment of educational presentations and scientific advice from Novartis, Pfizer and Roche. JoseMedina-Pestana has received speaker's fees and travel or accommodation expenses for development ofeducational presentations and scientific advice from Bristol- Myers Squibb, Novartis, Pfizer and Roche.Claudia Felipe has received speaker's fees for development of educational presentations and travel oraccommodation expenses from Novartis and Pfizer.

\section{Authors' contributions}

All authors made critical comments, suggestions and revisions to earlier drafts. All authors interpreted results, read and approved the final version of the manuscript.

\section{Acknowledgements}

We would like to thank Wyeth/Pfizer for the continuing research support provided to our transplant center.

\section{Declarations}

The article has been published as part of Transplantation Research Volume 4 Suppl 1, 2015: Proceedings of the 13th International Transplantation Symposia: mTOR-inhibition: what have we learned and how do we best apply the learning. The full content of the supplement can be found at $<$ http://www.transplantationresearch.com/supplements $>$. The symposium and publication were supported by an unrestricted educational grant from Pfizer Inc, who had no influence on the editorial content. Editorial support was provided by Synergy, Richmond, UK and was funded by Pfizer Inc. The articles have been through the journal's standard peer review process.

Published: 21 December 2015

\section{References}

1. Machado PG, Felipe CR, Hanzawa NM, Park SI, Garcia R, Alfieri F, et al. An open-label randomized trial of the safety and efficacy of sirolimus vs. azathioprine in living related renal allograft recipients receiving cyclosporine and prednisone combination. Clin Transplant. 2004;18:28-38.

2. Kahan BD. Efficacy of sirolimus compared with azathioprine for reduction of acute renal allograft rejection: a randomised multicentre study. The Rapamune US Study Group. Lancet. 2000;356 (9225):194-202. England.

3. MacDonald AS. A worldwide, phase III, randomized, controlled, safety and efficacy study of a sirolimus/cyclosporine regimen for prevention of acute rejection in recipients of primary mismatched renal allografts. Transplantation. 2001;71:271-80.

4. Machado PG, Felipe CR, Park SI, Garcia R, Moreira S, Casarini D, et al. Preservation of graft function in low-risk living kidney transplant recipients treated with a combination of sirolimus and cyclosporine. Braz J Med Biol Res. 2004;37 (9):1303-12. Brazil.

5. Medina-Pestana JO, Sampaio EM, Vaz ML, Pinheiro-Machado PG, TedescoSilva Jr H. Worse renal transplant outcomes observed among Afro-Brazilian patients on prospective registry data of 2461 renal transplants at least 1 year follow-up. Transplant Proc. 2007;39(2):435-6. United States.

6. Podder H, Podbielski J, Hussein I, Katz S, Van Buren C, Kahan BD. Sirolimus improves the two-year outcome of renal allografts in African-American patients. Transpl Int. 2001;14:135-42. 
7. Ferreira AN, Machado PG, Felipe CR, Motegi SA, Hosaka BH, Tanaka MK, et al. Concentration-controlled use of sirolimus associated with reduced exposure of cyclosporine in black recipients of primarily living renal allograft donors: 12-month results. Clin Transplant. 2005;19(5):607-15. Denmark.

8. Podder H, Stepkowski SM, Napoli KL, Clark J, Verani RR, Chou TC, et al. Pharmacokinetic interactions augment toxicities of sirolimus/cyclosporine combinations. J Am Soc Nephrol. 2001;12:1059-71.

9. Felipe CR, Park SI, Pinheiro-Machado PG, Garcia R, Casarini DE, Moreira S, et al. Cyclosporine and sirolimus pharmacokinetics and drug-to-drug interactions in kidney transplant recipients. Fundam Clin Pharmacol. 2009;23(5):625-31. England.

10. Groth CG, Bäckman L, Morales JM, Calne R, Kreis H, Lang P, et al. Sirolimus (rapamycin)-based therapy in human renal transplantation: similar efficacy and different toxicity compared with cyclosporine. Sirolimus European Renal Transplant Study Group. Transplantation. 1999;67:1036-42.

11. Kreis H, Cisterne JM, Land W, Wramner L, Squifflet JP, Abramowicz D, et al. Sirolimus in association with mycophenolate mofetil induction for the prevention of acute graft rejection in renal allograft recipients. Transplantation. 2000;69:1252-60.

12. Johnson RW, Kreis H, Oberbauer R, Brattström C, Claesson K, Eris J. Sirolimus allows early cyclosporine withdrawal in renal transplantation resulting in improved renal function and lower blood pressure. Transplantation. 2001:72:777-86.

13. Baboolal K. A phase III prospective, randomized study to evaluate concentration-controlled sirolimus (rapamune) with cyclosporine dose minimization or elimination at six months in de novo renal allograft recipients. Transplantation. 2003;75:1404-8.

14. Tedesco-Silva H, Garcia VD, Contieri FL, De Boni Monteiro de Carvalho D, Noronha IL, Goncalves RT, et al. Comparison of the safety and efficacy of cyclosporine minimization versus cyclosporine elimination in de novo renal allograft patients receiving sirolimus. Transplant Proc. 2010;42(5):1659-66. United States.

15. Legendre $C$, Brault $Y$, Morales JM, Oberbauer $R$, Altieri $P$, Riad $H$, et al. Factors influencing glomerular filtration rate in renal transplantation after cyclosporine withdrawal using sirolimus-based therapy: a multivariate analysis of results at five years. Clin Transplant. 2007;21:330-6.

16. Gonwa TA, Hricik DE, Brinker K, Grinyo JM, Schena FP, Group SRFS. Improved renal function in sirolimus-treated renal transplant patients after early cyclosporine elimination. Transplantation. 2002;74:1560-7.

17. Pliszczynski J, Kahan BD. Better actual 10-year renal transplant outcomes of $80 \%$ reduced cyclosporine exposure with sirolimus base therapy compared with full cyclosporine exposure without or with concomittant sirolimus treatment. Transplant Proc. 2011;43:3657-68.

18. Sampaio EL, Pinheiro-Machado PG, Garcia R, Felipe CR, Park SI, Casarini DE, et al. Mycophenolate mofetil vs. sirolimus in kidney transplant recipients receiving tacrolimus-based immunosuppressive regimen. Clin Transplant. 2008;22(2):141-9. Denmark.

19. Vitko S, Wlodarczyk Z, Kyllönen $L$, Czajkowski Z, Margreiter R, Backman L, et al. Tacrolimus combined with two different dosages of sirolimus in kidney transplantation: results of a multicenter study. Am J Transplant. 2006;6:531-8.

20. Gonwa T, Mendez R, Yang HC, Weinstein S, Jensik S, Steinberg S. Randomized trial of tacrolimus in combination with sirolimus or mycophenolate mofetil in kidney transplantation: results at 6 months. Transplantation. 2003;75:1213-20.

21. Bechstein WO, Paczek L, Wramner L, Squifflet JP, Zygmunt AJ, Group ERTS. A comparative, randomized trial of concentration-controlled sirolimus combined with reduced-dose tacrolimus or standard-dose tacrolimus in renal allograft recipients. Transplant Proc. 2013;45:2133-40.

22. Flechner SM, Glyda M, Cockfield S, Grinyó J, Legendre C, Russ G, et al. The ORION study: comparison of two sirolimus-based regimens versus tacrolimus and mycophenolate mofetil in renal allograft recipients. Am J Transplant. 2011;11:1633-44.

23. Garcia R, Machado PG, Felipe CR, Park SI, Spinelli GA, Franco MF, et al, Exploratory calcineurin inhibitor-free regimens in living-related kidney transplant recipients. Braz J Med Biol Res. 2007;40(4):457-65. Brazil.

24. Vincenti F, Ramos E, Brattstrom C, Cho S, Ekberg H, Grinyo J, et al. Multicenter trial exploring calcineurin inhibitors avoidance in renal transplantation. Transplantation. 2001;71:1282-7.

25. Flechner SM. Sirolimus in kidney transplantation indications and practical guidelines: de novo sirolimus-based therapy without calcineurin inhibitors. Transplantation. 2009;87:S1-6.
26. Flechner SM, Kobashigawa J, Klintmalm G. Calcineurin inhibitor-sparing regimens in solid organ transplantation: focus on improving renal function and nephrotoxicity. Clin Transplant. 2008;22:1-15.

27. de Sandes Freitas TV, Harada KM, Felipe CR, Galante NZ, Sampaio EL, Ikehara E, et al. Steroid or tacrolimus withdrawal in renal transplant recipients using sirolimus. Int Urol Nephrol. 2011;43:1221-8.

28. Augustine JJ, Hricik DE. Minimization of immunosuppression in kidney transplantation. Curr Opin Nephrol Hypertens. 2007;16:535-41.

29. Paula M, Hannun P, Felipe C, Ferreira A, Cristelli M, Franco M, et al. Long term follow up of de novo use of mTOR inhibitors (mTORi) after kidney transplantation. Am J Transplant. 2014;14:543-4.

30. Nashan B, Citterio F. Wound healing complications and the use of mammalian target of rapamycin inhibitors in kidney transplantation: a critical review of the literature. Transplantation. 2012;94:547-61.

31. Knight RJ, Kahan BD. The place of sirolimus in kidney transplantation: can we reduce calcineurin inhibitor renal toxicity? Kidney Int. 2006;70(6):994-9. United States.

32. Meier-Kriesche HU, Steffen BJ, Chu AH, Loveland JJ, Gordon RD, Morris JA, et al. Sirolimus with neoral versus mycophenolate mofetil with neoral is associated with decreased renal allograft survival. Am J Transplant. 2004:4:2058-66.

33. Meier-Kriesche HU, Schold JD, Srinivas TR, Howard RJ, Fujita S, Kaplan B. Sirolimus in combination with tacrolimus is associated with worse renal allograft survival compared to mycophenolate mofetil combined with tacrolimus. Am J Transplant. 2005;5:2273-80.

34. Yan HL, Zong HT, Cui YS, Li N, Zhang Y. Calcineurin inhibitor avoidance and withdrawal for kidney transplantation: a systematic review and metaanalysis of randomized controlled trials. Transplant Proc. 2014;46:1302-13.

35. Srinivas TR, Schold JD, Guerra G, Eagan A, Bucci CM, Meier-Kriesche HU. Mycophenolate mofetil/sirolimus compared to other common immunosuppressive regimens in kidney transplantation. Am J Transplant. 2007;7:586-94

36. Shihab F, Christians U, Smith L, Wellen JR, Kaplan B. Focus on mTOR inhibitors and tacrolimus in renal transplantation: pharmacokinetics, exposure-response relationships, and clinical outcomes. Transpl Immunol. 2014;31:22-32.

37. Schena FP, Pascoe MD, Alberu J, del Carmen Rial M, Oberbauer R, Brennan DC, et al. Conversion from calcineurin inhibitors to sirolimus maintenance therapy in renal allograft recipients: 24-month efficacy and safety results from the CONVERT trial. Transplantation. 2009;87(2):233-42. United States.

38. Weir MR, Mulgaonkar S, Chan L, Shidban H, Waid TH, Preston D, et al. Mycophenolate mofetil-based immunosuppression with sirolimus in renal transplantation: a randomized, controlled Spare-the-Nephron trial. Kidney Int. 2011;79(8):897-907. United States: 2011 International Society of Nephrology.

39. Silva HT, Felipe CR, Garcia VD, Neto ED, Filho MA, Contieri FL, et al. Planned randomized conversion from tacrolimus to sirolimus-based immunosuppressive regimen in de novo kidney transplant recipients. Am J Transplant. 2013;13:3155-63.

40. Tedesco-Silva H, Peddi V, Sanchez-Frutuoso A, Marder B, Russ G, Flynn A, et al. Open-label study of planned transition from tacrolimus to sirolimus vs continued tacrolimus in renal allograft. Am J Transplant. 2014;14:538-8.

41. Gatault P, Lebranchu Y. Conversion to mTOR-inhibitor-based immunosuppression: which patients and when? Transplant Res. 2013;2:S3.

42. Lebranchu Y, Thierry A, Toupance O, Westeel PF, Etienne I, Thervet E, et al. Efficacy on renal function of early conversion from cyclosporine to sirolimus 3 months after renal transplantation: concept study. Am J Transplant. 2009;9(5):1115-23. Denmark.

43. Thierry A, Thervet E, Vuiblet V, Goujon JM, Machet MC, Noel LH, et al. Longterm impact of subclinical inflammation diagnosed by protocol biopsy one year after renal transplantation. Am J Transplant. 2011;11:2153-61.

44. Servais A, Meas-Yedid V, Toupance O, Lebranchu Y, Thierry A, Moulin B, et al. Interstitial fibrosis quantification in renal transplant recipients randomized to continue cyclosporine or convert to sirolimus. Am J Transplant. 2009:9:2552-60.

45. Lebranchu Y, Thierry A, Thervet E, Büchler M, Etienne I, Westeel PF, et al. Efficacy and safety of early cyclosporine conversion to sirolimus with continued MMF-four-year results of the Postconcept study. Am J Transplant. 2011;11:1665-75.

46. Grinyó JM, Cruzado JM. Mycophenolate mofetil and sirolimus combination in renal transplantation. Am J Transplant. 2006;6:1991-9. 
47. Ferguson R, Grinyó J, Vincenti F, Kaufman DB, Woodle ES, Marder BA, et al. Immunosuppression with belatacept-based, corticosteroid-avoiding regimens in de novo kidney transplant recipients. Am J Transplant. 2011;11:66-76

48. Diekmann F, Andrés A, Oppenheimer F. mTOR inhibitor-associated proteinuria in kidney transplant recipients. Transplant Rev (Orlando). 2012;26:27-9.

49. Mandelbrot D, Alberu J, Barama A, Marder B, Tedesco-Silva H, Flynn A, et al. Effect of ramipril on urinary protein excretion in maintenance renal transplant patients converted to sirolimus. Am J Transplant. 2014;14:121-1.

50. Brennan DC, Aguado JM, Potena L, Jardine AG, Legendre C, Säemann MD, et al. Effect of maintenance immunosuppressive drugs on virus pathobiology: evidence and potential mechanisms. Rev Med Virol. 2013;23:97-125.

51. Nashan B, Gaston R, Emery V, Säemann MD, Mueller NJ, Couzi L, et al. Review of cytomegalovirus infection findings with mammalian target of rapamycin inhibitor-based immunosuppressive therapy in de novo renal transplant recipients. Transplantation. 2012;93:1075-85.

52. Suwelack $B$, Malyar $V$, Koch $M$, Sester $M$, Sommerer $C$. The influence of immunosuppressive agents on BK virus risk following kidney transplantation, and implications for choice of regimen. Transplant Rev (Orlando). 2012;26:201-11.

53. Vajdic CM, van Leeuwen MT. Cancer incidence and risk factors after solid organ transplantation. Int J Cancer. 2009;125:1747-54.

54. Geissler EK, Schlitt HJ. The potential benefits of rapamycin on renal function, tolerance, fibrosis, and malignancy following transplantation. Kidney Int. 2010;78:1075-9.

55. Hoogendijk-van den Akker JM, Harden PN, Hoitsma AJ, Proby CM, Wolterbeek R, Bouwes Bavinck JN, et al. Two-year randomized controlled prospective trial converting treatment of stable renal transplant recipients with cutaneous invasive squamous cell carcinomas to sirolimus. J Clin Oncol. 2013;31:1317-23.

56. Euvrard S, Morelon E, Rostaing L, Goffin E, Brocard A, Tromme I, et al. Sirolimus and secondary skin-cancer prevention in kidney transplantation. N Engl J Med. 2012;367:329-39.

57. Campbell SB, Walker R, Tai SS, Jiang Q, Russ GR. Randomized controlled trial of sirolimus for renal transplant recipients at high risk for nonmelanoma skin cancer. Am J Transplant. 2012;12:1146-56.

58. Christians U, Gottschalk S, Miljus J, Hainz C, Benet LZ, Leibfritz D, et al. Alterations in glucose metabolism by cyclosporine in rat brain slices link to oxidative stress: interactions with mTOR inhibitors. Br J Pharmacol. 2004; 143:388-96.

59. Bohra R, Schöning W, Klawitter J, Brunner N, Schmitz V, Shokati T, et al. Everolimus and sirolimus in combination with cyclosporine have different effects on renal metabolism in the rat. PLoS One. 2012;7:e48063.

60. Russ GR, Tedesco-Silva H, Kuypers DR, Cohney S, Langer RM, Witzke O, et al. Efficacy of sotrastaurin plus tacrolimus after de novo kidney transplantation: randomized, phase II trial results. Am J Transplant. 2013;13:1746-56.

61. Tedesco-Silva H, Kho MM, Hartmann A, Vitko S, Russ G, Rostaing L, et al. Sotrastaurin in calcineurin inhibitor-free regimen using everolimus in de novo kidney transplant recipients. Am J Transplant. 2013;13:1757-68.

62. Vincenti F, Tedesco Silva H, Busque S, O'Connell P, Friedewald J, Cibrik D, et al. Randomized phase 2b trial of tofacitinib (CP-690,550) in de novo kidney transplant patients: efficacy, renal function and safety at 1 year. Am J Transplant. 2012;12:2446-56.

63. Silva HT, Yang HC, Abouljoud M, Kuo PC, Wisemandle K, Bhattacharya P, et al. One-year results with extended-release tacrolimus/MMF, tacrolimus/MMF and cyclosporine/MMF in de novo kidney transplant recipients. Am J Transplant. 2007;7:595-608.

64. Budde K, Bunnapradist S, Grinyo JM, Ciechanowski K, Denny JE, Silva HT, et al. Novel once-daily extended-release tacrolimus (LCPT) versus twice-daily tacrolimus in de novo kidney transplants: one-year results of phase III, double-blind, randomized trial. Am J Transplant. 2014;2014:2796-806.

65. Bestard O, Cassis L, Cruzado JM, Torras J, Franquesa M, Gil-Vernet S, et al. Costimulatory blockade with mTor inhibition abrogates effector T-cell responses allowing regulatory T-cell survival in renal transplantation. Transpl Int. 2011:24:451-60.

66. Kim EJ, Kwun J, Gibby AC, Hong JJ, Farris AB, Iwakoshi NN, et al. Costimulation blockade alters germinal center responses and prevents antibody-mediated rejection. Am J Transplant. 2014;14:59-69.

\section{Submit your next manuscript to BioMed Central and take full advantage of:}

- Convenient online submission

- Thorough peer review

- No space constraints or color figure charges

- Immediate publication on acceptance

- Inclusion in PubMed, CAS, Scopus and Google Scholar

- Research which is freely available for redistribution 